\title{
When the North Atlantic caught a chill
}

\section{Surface cooling could have pushed down temperatures in the Northern Hemisphere 40 years ago.}

\section{BY QUIRIN SCHIERMEIER}

$\mathrm{T}$ Three-tenths of a degree may seem a small dip - but, for climate researchers, the discovery that a large patch of the ocean cooled by $0.3^{\circ} \mathrm{C}$ within a few years around 1970 is a small sensation.

"When averaged over an entire hemisphere, $0.3^{\circ} \mathrm{C}$ is fairly large," says David Thompson, an atmospheric scientist at Colorado State University in Fort Collins. Centred in the North Atlantic Ocean, the sudden cooling event that Thompson and his colleagues report ${ }^{1}$ on page 444 of this issue could help to solve a mystery: a prominent drop in the global mean surface temperature record around the same time. The ocean cooling, which may have resulted from a shift in currents, also offers a reminder of the North Atlantic's outsize role in climate.

The scientists had spotted the anomaly when reanalysing records of sea surface temperature. Ship-based temperature measurements can be misleading; in 2008 , the same team showed that a supposed $0.3^{\circ} \mathrm{C}$ drop in global mean temperatures in 1945 actually reflected a change in shipboard measurement techniques after the war ${ }^{2}$. So before concluding that the new anomaly was real, says co-author Phil Jones of the Climatic Research Unit at the University of East Anglia in Norwich, UK, "we spent a lot of time in trying to rule out possible data issues".

What caused the sea surface cooling around 1970 is unclear. But Rowan Sutton of the National Centre for Atmospheric Sciences in Reading, UK, suspects that currents are responsible. "The spatial pattern of the event strongly suggests it has to do with a sudden change in the Atlantic meridional overturning circulation" - the northward flow of warm surface water as colder water moves southwards at greater depths - he says.

"We need to understand the circumstances in which this happens," adds Sutton, who has studied ways of predicting abrupt circulation changes ${ }^{3}$. A temporary pool of low-salinity water in the North Atlantic called the Great Salinity Anomaly coincided with the cooling, suggest-

ONATURE.COM La Niña's return will prompt global weather change. go.nature.com/7Cfszd ing that an influx of fresh water was the trigger. "If further research helps show that the two events are related, this could provide a way to further test modelled ocean responses to freshwater additions from the Arctic," says Gavin Schmidt, a climate modeller at the NASA Goddard Institute for Space Studies in New York City. Scientists believe that global warming will increase freshwater flow into the North Atlantic.

The ocean cooling also coincides with a $0.2^{\circ} \mathrm{C}$ drop in global mean temperature from the late 1960s to the mid-1970s (see graphic). Researchers have blamed this short-lived cooling, more pronounced in the Northern Hemisphere, on a build-up of sunlight-blocking sulphate aerosols

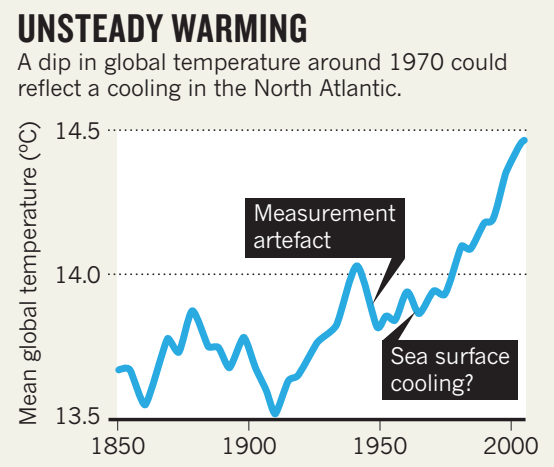

from fossil fuels, which began to clear in the 1970 s as pollution controls took hold.

Thompson and his colleagues think a circulation change in the North Atlantic is a more likely culprit. But Michael Mann, a climate researcher at Pennsylvania State University in University Park, isn't so sure. He thinks that aerosols probably contributed to the global chill, and that the ocean cooling was probably the steep end of a natural climate oscillation spanning several decades. "I'm unconvinced they've shown that the model of an isolated brief event is a better fit to the data."

For Jones, the scientific debate comes as a welcome change. For the past year he has been at the centre of a controversy after allegedly compromising climate e-mails were stolen from his computer. Jones and his co-workers have been cleared of any scientific misconduct, and he says, "It's definitely good to finally talk about real science again".

1. Thompson, D. W. J., Wallace, J. M., Kennedy, J. J. \& Jones, P. D. Nature 467, 444-447 (2010).

2. Thompson, D. W. J., Kennedy, J. J., Wallace, J. M. \& Jones, P. D. Nature 453, 646-649 (2008).

3. Hawkins, E. \& Sutton, R. Geophys. Res. Lett. 35 L11603 (2008) 